9. Халшев В.Е. Композиция // Литературная энциклопедия терминов и понятий / Гл. ред. и сост. А.Н. Николюкин. М.: Интелвак, 2001. С. 387-388.

10. Eco U. Postille al nome della rosa. Added to the pocket italian edition, Milano: Bompiani (Commented edition, ed. by Costantino Marmo. Milano: Edizioni Scolastiche Fabbri), 1984. $48 \mathrm{c}$.

11. Кожинов В.В. Композиция // Краткая литературная энциклопедия / Гл. ред. А.А. Сурков: В 9 т. Т. 3. М.: Советская энциклопедия, 1978. С. 694-696.
12. Композиция // Музыкальная энциклопедия / ред. Ю.В. Келдыш: В 6 т. Т. 2. М.: Советская энциклопедия. Советский композитор, 1974. С. 892-895.

13. Лучинская Е.Н. Постмодернистский дискурс: автореф. дис. ... канд. филол. наук. Краснодар, 2002. $46 \mathrm{c}$.

14. Куприянова Л.А. Семантика музыкальной композиции: автореф. дис. ... канд. иск. Магнитогорск, 2000. $24 \mathrm{c}$.

\title{
CONTESTS OF CONCEPT «ART-COMPOSITION» IN CONTEXT OF XXI CENTURY ART EDUCATION
}

\section{(C) 2016}

L.Yu. Kalinina, candidate of pedagogical sciences, associate professor of the Chair of Musical Education Samara State University of Social Sciences and Education, Samara (Russia)

Abstract. The article discusses the concept of «art composition», that functioning in practice music teachers, teachers of fine arts and literature, teachers of choreography and theater. However, the theoretical foundation of artcomposition and content of the concept has not yet been the subject of a special study. At the same time, comprehension of innovative approach in educating to the art, maintenance of artistic education characterized by an orientation on studying - man with a modern world view, it is necessary. A necessity of enriching of thesaurus of school pedagogics was clear, actual terms, «art composition» behaves to the number of that. This study contributes to the problem of a more general nature - the possibility of using polyart creative activities as a means of identification and learning of gifted children. The originality of the art-composition - in the innovative thinking of the modern author, whose seeking to portray the world is not the way it sees, but the way it understands. Results of the creative work can be presented in different art forms, not excluding sketches, improvisations, postmodern «games» with the text. The pedagogical value of the art-composition: the teacher can visually track the progress of the child in the field of aesthetic perception, associative thinking and the work with the material.

Keywords: art education; art composition; concepts of pedagogics; polyart creativity of children; creative process; innovative pedagogics; modern art; active approach is in education; post-modern; rhizome; «creating chaos»; expressive facilities of art.

УДК 378

\section{ОСОБЕННОСТИ РАЗРАБОТКИ И ВНЕДРЕНИЯ КУРСОВ ОБРАЗОВАТЕЛЬНОЙ ОБЛАСТИ «МАТЕМАТИКА» В СИСТЕМЫ ДИСТАНЦИОННОГО ОБУЧЕНИЯ}

(C) 2016

Е.Л. Макарова, кандидат педагогических наук, доцент кафедры информатики, прикладной математики и методики их преподавания

О.И. Пугач, кандидат педагогических наук,

доцент кафедры информатики, прикладной математики и методики их преподавания Самарский государственный сочиально-педагогический университет, Самара (Россия)

\begin{abstract}
Аннотация. Эффективное применение дистанционных технологий даже на уровне отдельных курсов в большинстве вузов сталкивается с целым рядом организационных, методических проблем. Окончательное оформление нормативной базы проблему внедрения указанных технологий из области теоретического исследования и опытно-экспериментальной работы в плоскость практического внедрения. Авторы рассматривают широкий спектр проблем, возникающих при массовом внедрении систем дистанционного обучения в образовательную практику, их классификацию по различным основаниям. При выполнении работы авторы опираются на практический опыт разработки курса «Математические основы информатики» для студентов направления подготовки «Педагогическое образование» профилей «Информатика» и «Информатика и Иностранный язык» на базе системы управления обучением Moodle. Также изучается ряд аспектов, связанных с особенностями изучаемой предметной области (на примере образовательной области «Математика»). Формулируются необходимые условия эффективности применения технологий электронного обучения. Такими условиями, с точки зрения авторов статьи, выступают, в числе прочих участие в процессе внедрения администрации вуза, формирование однородной по уровню базовой математической подготовки группы студентов, формирование тезауруса (семантической сети) курса в процессе аудиторной работы со студентами, а также поэтапный подход к решению сложных текстовых заданий, требующих построения формальной математической модели в предметной области. Предлагаются некоторые простые критерии оценки эффективности (повышение успеваемости и мотивации студентов, оптимизация по времени работы преподавателя, уменьшение количества хронических задолжников по дисциплине).
\end{abstract}


Ключевые слова: дистанционное обучение; курсы; внедрение; образовательная область «Математика»; экономическая эффективность; учебный план; рабочая программа; организация самостоятельной работы студентов; экспертиза дидактических материалов; инновации; внедрение дистанционных технологий обучения; электронные образовательные ресурсы.

Различные подходы к электронному обучению, дистанционным образовательным технологиям системно и комплексно изучались в целом ряде фундаментальных педагогических исследований (М.Е. Бершадский, Я.А. Ваграменко, В.В. Вержбицкий, А.Д. Иванников, В.С. Лазарев, С.Л. Лобачев, Э.А. Манушин, О.П. Молчанова, В.И. Овсянников, Е.С. Полат, Е.Е. Попов, В.И. Солдаткин, Л.Г. Титарев, А. Поляков, И.В. Роберт, Т.О. Хубаев, А.В. Хуторской, Д.В. Чернилевский, С.А. Щенников и др.). Окончательное оформление нормативной базы, в частности принятие последней редакции закона РФ «Об образовании» перевело проблему из области теоретического исследования и опытно-экспериментальной работы в плоскость практического внедрения в повседневную деятельность образовательных учреждений всех уровней: «Организации, осуществляющие образовательную деятельность, вправе применять электронное обучение, дистанционные образовательные технологии при реализации образовательных программ в порядке, установленном федеральным органом исполнительной власти, осуществляющим функции по выработке государственной политики и нормативноправовому регулированию в сфере образования» [1].

Эффективное применение дистанционных технологий (здесь и далее мы руководствуемся определениями электронного обучения и дистанционных образовательных технологий, приведенных в Законе «Об образовании») даже на уровне отдельных курсов в большинстве вузов сталкивается с целым рядом организационных, методических проблем [2-9]. Рассмотрим вариант их классификации в соответствии со следующим основаниями: зависимость от конкретной дисциплины (предметной области), и методы их решения.

Обозначим проблему как инвариантную, если она присуща любому дистанционному курсу (по тем дисциплинам, которые допускают такую технологию изучения).

Будем называть проблему предметно-зависимой, если она присуща, лишь некоторому классу дисциплин (образовательных областей).

Проблема относится к категории методических, если методы ее решения лежат в области дидактики, методики преподавания дисциплины, педагогической технологии.

Проблема относится к категории организационных, если ее решение требует модернизации нормативной базы, разработки локальных актов, управленческих решений, изменения схем финансирования или объемов.

Итоговая классификация представлена в табл. 1. Здесь и далее в тексте статьи в качестве примера для иллюстрации предметно-зависимых проблем (факторов) будем использовать образовательную область «Математика» (как более знакомую авторам).

Как правило, студенты встречают электронное обучение с гораздо большим энтузиазмом, чем преподаватели. Дистанционный курс (или ЭОР) обеспе- чивает им потенциальную возможность свободного посещения, прозрачность и единство (для всех студентов группы) требований преподавателя. Тем не менее, ряд проблем возникает и у обучающихся, их неполный перечень представлен в таблице 2.

Теоретическое исследование было решено дополнить экспериментальной работой по созданию, экспертизе и внедрению электронного курса. Технологической платформой выступила система управления обучением (LMS) Moodle.

Требования ФГОС 3+, ФГОС 4, которые необходимо учитывать при построении электронной информационно-образовательной среды (ЭИОС) вуза, накладывают ограничения на выбор информационной системы, обеспечивающей практическую реализацию ЭИОС вуза. Платформа электронного обучения Moodle предоставляет широкие возможности для организации процесса обучения, проведения контроля и анализа результатов работы студентов. LMS Moodle распространяется по лицензии GNU/GPL это позволяет, при необходимости, адаптировать ее под особенности конкретного образовательного проекта, встроить новые модули. [10; 11]

Moodle поддерживает систему портфолио, включающего: работы студента, оценки и комментарии преподавателя к ним, все сообщения на форуме, дополнительные материалы. В рамках курса преподаватель имеет возможность применять удобную для него систему оценивания $[12 ; 13 ; 14]$. Результаты по каждому курсу могут быть представлены в виде сводной ведомости, есть возможности контроля времени работы студента с конкретным курсом.

В рамках исследования проблемы использования электронного обучения как базовой технологии, авторами был разработан, размещен в системе Moodle, апробирован и внедрен курс «Математические основы информатики». Целью учебной дисциплины «Математические основы информатики» является формирование информационной картины мира, отражающей основные подходы к пониманию роли и значения информации в современном мире, принципы и этапы информационных процессов; наиболее широко используемые классы информационных моделей и основные математические методы получения, хранения, обработки, передачи и использования информации; математический аппарат анализа и синтеза информационных систем; принципы решения практических задач хранения и обработки информации. Дисциплина относится к вариативной части математического и естественнонаучного цикла. Общая трудоемкость дисциплины составляет 2 зачетные единицы. Всего 72 часа. Аудиторные занятия 32 часа, в том числе интерактивных занятий 20 часов. Самостоятельная работа 40 часов.

Структура и содержание курса представлены в таблице 3.

Курс был размещен в системе Moodle (рис. 1) [1011] и апробирован в рамках смешанной (очная и дистанционная) модели обучения. 
В процессе разработки, корректировки и внедрения курса «Математические основы информатики» удалось выявить ряд технических особенностей, су-

Таблица 1 - Классификация факторов, препятствующих эффективному использованию дистанционных технологий преподавателем

\begin{tabular}{|c|c|c|}
\hline & Инвариантные & Предметно-зависимые \\
\hline & $\begin{array}{l}\text { - сложность отбора содержания в соответствии с уровнем } \\
\text { подготовки студента; } \\
\text { - повышенная ответственность преподавателя за кор- } \\
\text { ректность фактов, решений, стандартизацию и унифика- } \\
\text { цию обозначений; } \\
\text { - невозможность изменения содержимого курса «на ле- } \\
\text { ту», в зависимости от уровня подготовки обучающихся; } \\
\text { - принципиально иной подход к диагностике и формиро- } \\
\text { ванию заданий, предусматривающий сплошной контроль } \\
\text { усвоения каждого понятия, определения, формулы; } \\
\text { - невозможность предотвратить «списывание» без созда- } \\
\text { ния достаточно большого банка промежуточных и итого- } \\
\text { вых заданий. }\end{array}$ & $\begin{array}{l}\text { - отсутствие методик и технологий балансиро- } \\
\text { вания текстовой, графической, аудиальной и } \\
\text { визуальной форм представления информации } \\
\text { (при очной работе преподаватель легко меняет } \\
\text { их «на лету»: проговаривает определения из } \\
\text { методического пособия, рисует дополнитель- } \\
\text { ные схемы, разбирает примеры в динамике - в } \\
\text { дистанционной форме оптимальное их соот- } \\
\text { ношение должно быть найдено заранее); } \\
\text { - изменение методических особенностей рабо- } \\
\text { ты преподавателя и студента при использова- } \\
\text { нии открытых заданий (подробное решение за- } \\
\text { дач, написание программного кода, конструи- } \\
\text { рование детали и т.д.) (подготовка машинного } \\
\text { варианта работы занимает у студента значи- } \\
\text { тельно больше времени, при этом получение } \\
\text { подсказки в процессе работы осложнено; при- } \\
\text { ходится или дублировать объяснение типовых } \\
\text { проблем и ошибок или включать дополнитель- } \\
\text { ные пояснения в текст курса). }\end{array}$ \\
\hline & $\begin{array}{l}\text { - проблемы корректного использования и распростране- } \\
\text { ния (юридический и этический аспекты) чужих методи- } \\
\text { ческих материалов; } \\
\text { - вопрос эффективности временных затрат при широком } \\
\text { спектре различных курсов и дисциплин (у преподавате- } \\
\text { ля); при регулярных изменениях учебных планов; } \\
\text { - необходимость освоения нового программного продук- } \\
\text { та, решения организационно-технических вопросов по } \\
\text { размещению и организации доступа к курсу; } \\
\text { - нежелание преподавателей распространять/публиковать } \\
\text { авторские материалы без соответствующей компенсации } \\
\text { (вопрос сохранения авторских прав); } \\
\text { - затраченное время преподавателя и студента обратно } \\
\text { связано - чем свободней график студента при выполне- } \\
\text { нии работ, тем больше времени тратит преподаватель на } \\
\text { оценку, проверку и корректировку. }\end{array}$ & $\begin{array}{l}\text { - существенный объем технической работы по } \\
\text { набору текста с формулами; } \\
\text { - невозможность полного отказа от классиче- } \\
\text { ских методов контроля, и как следствие, уве- } \\
\text { личение работы преподавателя. }\end{array}$ \\
\hline
\end{tabular}

Таблица 2 - Классификация факторов, препятствующих эффективному использованию дистанционных технологий студентом

\begin{tabular}{|c|c|c|}
\hline & Инвариантные & Предметно-зависимые (Математика) \\
\hline 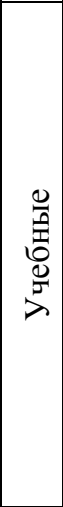 & $\begin{array}{l}\text { - технические проблемы использования интерфейса си- } \\
\text { стемы дистанционного обучения (системы управления } \\
\text { обучением); } \\
\text { - неравномерность подготовки, и, как следствие - отсут- } \\
\text { ствие базы для выполнения практических заданий; } \\
\text { - недостаточные навыки анализа материала дисциплины } \\
\text { (проблемы тезауруса, памяти, навыков анализа текста). }\end{array}$ & $\begin{array}{l}\text { - с трудом формируется навык чтения матема- } \\
\text { тического текста, записи со слуха; } \\
\text { - трудность освоения процесса формализации, } \\
\text { вызванные отсутствием неформальных приме- } \\
\text { ров; } \\
\text { - замена мягкой обратной связи на жесткую } \\
\text { (то есть правильно решенная задача с числовой } \\
\text { ошибкой при проверке в тестовой форме будет } \\
\text { считаться решенной неверно); } \\
\text { - потеря имплицитных механизмов формиро- } \\
\text { вания преподавательских навыков (для буду- } \\
\text { щих учителей математики-информатики). }\end{array}$ \\
\hline
\end{tabular}


Макарова Е.Л., Пугач О.И.

Особенности разработки и внедрения курсов образовательной области...

13.00.00 - педагогические науки

\begin{tabular}{|c|c|c|}
\hline 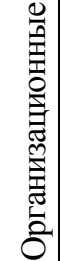 & $\begin{array}{l}\text { - неразвитые умения в области самоорганизации и само- } \\
\text { менеджмента, сложность работы в условиях мягкого } \\
\text { управления процессом обучения; } \\
\text { - проблемы, возникающие при возникновении форс- } \\
\text { мажорных обстоятельств (пропуск крайних сроков сдачи } \\
\text { работ по уважительной причине, технические сбои и т.п.) }\end{array}$ & $\begin{array}{l}\text { - несоответствие форм контроля возможно- } \\
\text { стям конкретного студента } \\
\text { - проблемы с развитием общих (мета) компе- } \\
\text { тенций (публичных выступлений, дискуссий, } \\
\text { управления и т.п.) }\end{array}$ \\
\hline
\end{tabular}

Таблица 3 - Содержание модулей дисциплины

\begin{tabular}{|c|l|l|}
\hline $\begin{array}{c}\text { № } \\
\text { п/п }\end{array}$ & \multicolumn{1}{|c|}{$\begin{array}{l}\text { Наименование разделов дисци- } \\
\text { плины, тем }\end{array}$} & \multicolumn{1}{|c|}{ Содержание темы } \\
\hline \multicolumn{1}{|c|}{$\begin{array}{l}\text { Модуль «Теория информации» } \\
1\end{array}$} & $\begin{array}{l}\text { Информация как фундамен- } \\
\text { наукия категория современной }\end{array}$ & $\begin{array}{l}\text { Различные трактовки понятия «информации». Виды и свойства инфор- } \\
\text { мации. Непрерывная и дискретная информация. Информационные про- } \\
\text { цессы: примеры. }\end{array}$ \\
\hline 2 & Энтропия и информация & $\begin{array}{l}\text { Энтропия и информация. Вероятностный и алфавитный подходы к из- } \\
\text { мерению информации. }\end{array}$ \\
\hline 3 & $\begin{array}{l}\text { Кодирование информации } \\
\text { Мостановка задачи кодирования. Коды постоянной и переменной дли- } \\
\text { ны: определения и примеры. Код переменной длины с разделителем. } \\
\text { Условие Фано. Префиксные коды. Код Шеннона-Фано. Префиксный } \\
\text { код Хаффмана. Байтовое кодирование. }\end{array}$ \\
\hline 5 & $\begin{array}{l}\text { Системы счисления } \\
\text { лых чисел в компьютере }\end{array}$ & $\begin{array}{l}\text { Системы счисления. Двоичная система счисления, операции над дво- } \\
\text { ичными числами. }\end{array}$ \\
\hline 6 & $\begin{array}{l}\text { Представление и обработка } \\
\text { вещественных чисел в компью- } \\
\text { тере }\end{array}$ & $\begin{array}{l}\text { Кодирование и обработка в компьютере целых чисел без знака. Коди- } \\
\text { рование и обработка целых чисел со знаком. }\end{array}$ \\
\hline
\end{tabular}
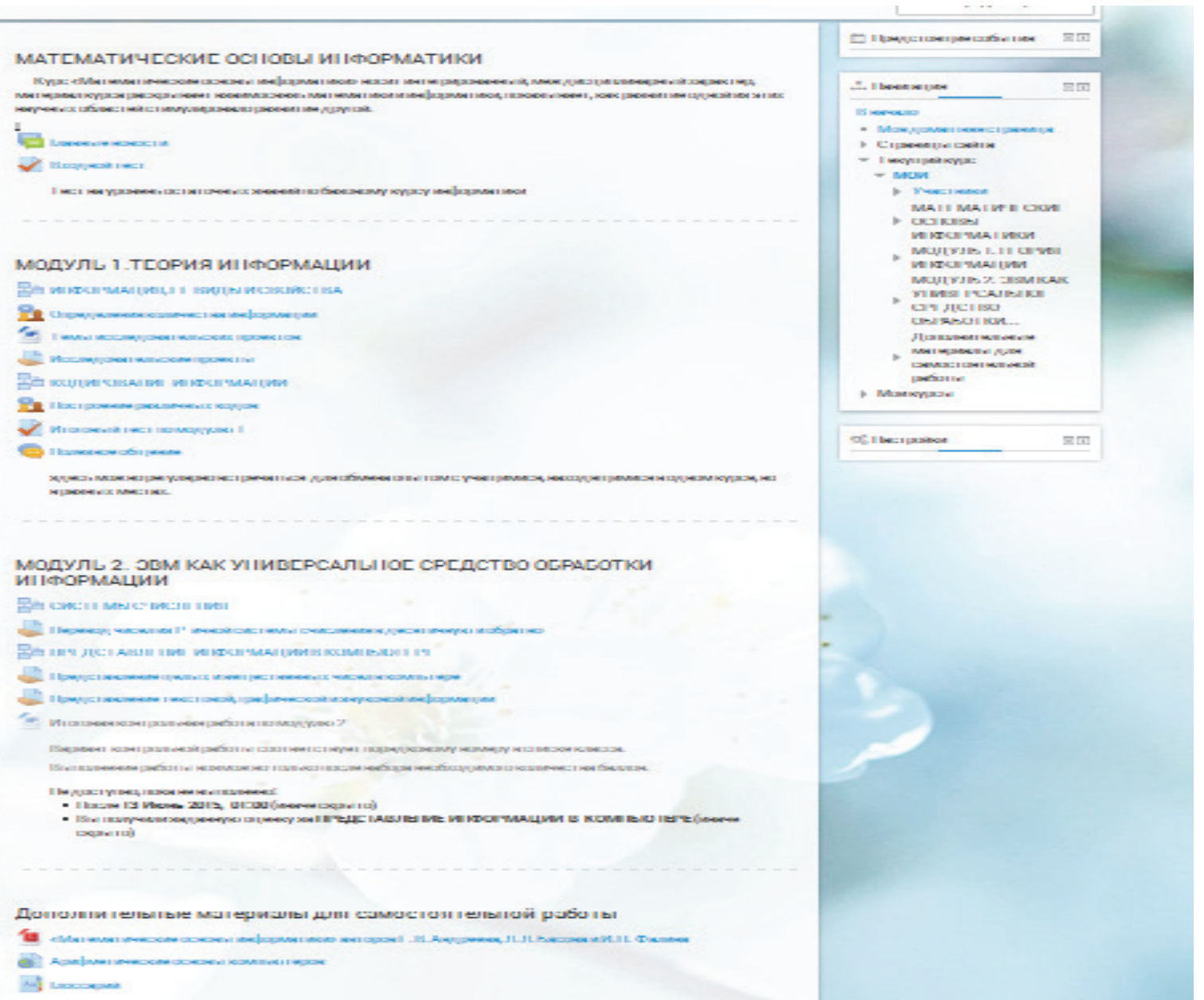

Рисунок 1 - Вид курса в системе Moodle 
Таблица 4 - Содержание модулей дисциплины, их технические особенности

\begin{tabular}{|c|c|c|c|c|c|c|}
\hline \multirow{2}{*}{$\begin{array}{c}\text { Наименование } \\
\text { разделов дисципли- } \\
\text { ны, тем }\end{array}$} & \multirow{2}{*}{ Содержание темы } & \multicolumn{5}{|c|}{$\begin{array}{l}\text { Технические особенности } \\
\text { лекционного материала* }\end{array}$} \\
\hline & & 1 & 2 & 3 & 4 & 5 \\
\hline \multicolumn{7}{|c|}{ Модуль «Теория информации» } \\
\hline $\begin{array}{l}\text { Информация как } \\
\text { фундаментальная } \\
\text { категория совре- } \\
\text { менной науки }\end{array}$ & $\begin{array}{l}\text { Различные трактовки понятия «информации». Виды и } \\
\text { свойства информации. Непрерывная и дискретная ин- } \\
\text { формация. Информационные процессы: примеры }\end{array}$ & - & \pm & \pm & - & + \\
\hline $\begin{array}{l}\text { Энтропия и инфор- } \\
\text { мация }\end{array}$ & $\begin{array}{l}\text { Энтропия и информация. Вероятностный и алфавитный } \\
\text { подходы к измерению информации }\end{array}$ & \pm & - & \pm & + & + \\
\hline $\begin{array}{l}\text { Кодирование ин- } \\
\text { формации }\end{array}$ & $\begin{array}{l}\text { Постановка задачи кодирования. Коды постоянной и пе- } \\
\text { ременной длины: определения и примеры. Код перемен- } \\
\text { ной длины с разделителем. Условие Фано. Префиксные } \\
\text { коды. Код Шеннона-Фано. Префиксный код Хаффмана. } \\
\text { Байтовое кодирование }\end{array}$ & \pm & + & \pm & + & + \\
\hline \multicolumn{7}{|c|}{ Модуль «ЭВМ как универсальное средство обработки информации» } \\
\hline Системы счисления & $\begin{array}{l}\text { Системы счисления. Двоичная система счисления, } \\
\text { операции над двоичными числами }\end{array}$ & \pm & + & \pm & + & + \\
\hline $\begin{array}{l}\text { Представление и } \\
\text { обработка целых } \\
\text { чисел в компьютере }\end{array}$ & $\begin{array}{l}\text { Кодирование и обработка в компьютере целых чисел без } \\
\text { знака. Кодирование и обработка целых чисел со знаком }\end{array}$ & \pm & \pm & \pm & + & + \\
\hline $\begin{array}{l}\text { Представление и } \\
\text { обработка } \\
\text { вещественных чисел } \\
\text { в компьютере }\end{array}$ & $\begin{array}{l}\text { Нормализованные числа, операции над ними. Погреш- } \\
\text { ность вычислений при обработке вещественных чисел. } \\
\text { Проблемы представления данных }\end{array}$ & \pm & \pm & \pm & + & + \\
\hline
\end{tabular}

*Примечание: 1 - значительное количество формул и расчетов; 2 - значительное количество и сложность графических блоков; 3 - необходимость выделения блоков текста стилевым оформлением; 4 - многообразие типов практических заданий; 5 - необходимость дополнительной (после размещения материалов) научной редактуры и корректуры

Проведенная работа показала, что разработка курca в Moodle эквивалентна по сложности написанию учебно-методического пособия. При этом к преимуществам Moodle можно отнести возможность частичной или поэтапной публикации учебных материалов, встроенные механизмы для совместной работы нескольких преподавателей, возможность привлечения студенческих фокус-групп для тестирования, проверки материалов. Однако в образовательной области «Математика» эти преимущества нивелируются рядом технических (необходимость работы с формулами, сложности в автоматизации процессов проверки выполненных заданий) и методических трудностей. Одной из основных методических проблем при этом становится подбор степени подробности изложения решаемых задач. Использование максимально развернутых доказательств и решений усложняет работу преподавателя, применение сокращений «легко видеть», характерное для учебников университетского типа по различным разделам высшей математики делает их непонятными для студентов среднего и ниже среднего уровня подготовки. Использование вариативного подхода, когда уровень изложения выбирается в соответствии с возможностями студента, увеличивает трудозатраты на разработку курса в несколько раз.
На основе опыта практической работы [15-21] была выдвинута гипотеза, что необходимыми условиями для эффективного применения дистанционных технологий в образовательной области «Математика» выступают:

а) на предварительном этапе:

- наличие организационной поддержки со стороны администрации вуза;

- готовность студента к самостоятельной работе с отдельными темами (разделами) курса;

- формирование достаточно однородной по уровню базовой математической подготовки группы студентов;

- оценка экономической эффективности внедрения смешанной модели в условиях конкретного вуза (при малочисленных группах разработка и внедрение могут оказаться финансово нецелесообразными);

б) в процессе организации дистанционного и/или смешанного обучения:

- формирование тезауруса (семантической сети) курса в процессе аудиторной работы;

- присутствие в системе модуля, позволяющего устранить недостатки в базовой подготовке студентов;

- поэтапный подход к решению сложных текстовых заданий, требующих построения формальной математической модели в предметной области. 
Об эффективности внедрения смешанной или дистанционной модели обучения на базе LMS Moodle можно судить по таким критериям, как повышение успеваемости и мотивации студентов, оптимизация по времени работы преподавателя, уменьшение количества хронических задолжников по дисциплине.

\section{СПИСОК ЛИТЕРАТУРЫ:}

1. Федеральный закон от 29 декабря 2012 г. N 273-Ф3 «Об образовании в Российской Федерации».

2. Пугач В.И., Тюжина И.В. Принципы организации учебного процесса: критичность и креативность // Гуманитарные науки в XXI веке. 2014. № 18. C. 200-205.

3. Пугач В.И., Тюжина И.В. Принципы рационального сочетания различных форм и методов изучения курса «Основы математической обработки информации» // Тенденции формирования науки нового времени: Материалы международной научно-практической конференции. 27-28 декабря 2013 г. Уфа: Изд. Башкирского государственного университета, 2014. С. $173-178$.

4. Добудько Т.В. Организация самостоятельной работы студентов в сети Интернет: формы и содержание // Ученые записки ИИО РАО. 2006. № 21. C. $74-75$.

5. Павлов В.Ю., Люсев В.Н. «Технология дистанционного обучения» с точки зрения педагогической науки // Современные информационные технологии. 2010. № 11. C. 111-113.

6. Гогицаева О.У., Кочисов В.К. Роль дистанционного образования в современных условиях // Азимут научных исследований: педагогика и психология. 2013. № 4. С. 10-12.

7. Ахметова Д.З. Обеспечение качества дистанционного обучения в призме личностного развития обучающихся // Карельский научный журнал. 2013. № 4. C. 55-58.

8. Иванова Т.Н. Тенденции и перспективы дистанционного образования // Азимут научных исследований: педагогика и психология. 2015. № 2 (11). C. $42-45$.

9. Кучай А.В. Интеграция мультимедийных технологий в процесс обучения // Балтийский гуманитарный журнал. 2014. № 4. С. 85-87.

10. Горбатов С.В. Использование систем управления обучением в процессе организации самостоятельной работы студентов // Модернизация профессионального образования: новые тенденции в управлении инновационным развитием экономических вузов: Материалы Всероссийской научно-практической конференции студентов, аспирантов и молодых ученых. Самара, 2013. С. 99-102.

11. Горбатов С.В. Методика использования системы управления в образовательном процессе учебного заведения // Поволжский педагогический вестник. 2014. № 3 (4). С. 90.

12. Аниськин В.Н., Добудько Т.В. Формирование и развитие учебных умений магистров педобразования при изучении дисциплины «Оценка качества знаний в системе дистанционного образования» // Формирование учебных умений: Материалы 3-й
Международной научно-практической конференции. 21-22 ноября 2014 г. Ульяновск: ФГБОУ ВПО «УлГПУ им. И.Н. Ульянова», 2014. С. 10-13.

13. Аниськин В.Н., Горбатов С.В., Добудько А.В., Добудько Т.В., Пугач В.И. Оценивание компетентности специалиста в области информатики в условиях современной электронной информационно-образовательной среды вуза // Математическое, естественнонаучное образование и информатизация: бюллетень лаборатории математического, естественнонаучного образования и информатизации: материалы международной научно-практической конференции: 2223 октября 2015 г. Самара; М.: СФ МГПУ, МГПУ, 2015. C. 52-58.

14. Аниськин В.Н., Добудько Т.В., Котова Т.А. Холистичный синергетический потенциал современной образовательной среды вуза как фактор повышения качества подготовки будущих специалистов // Известия Самарского научного центра Российской академии наук. 2014. Т. 16. № 2(4). С. 796-799.

15. Казеев А.Е. Организация математической подготовки бакалавров направления подготовки «Прикладная информатика» с использованием информационной технологий // Информационные технологии в социальной сфере: Материалы международной заочной научно-практической конференции. 29-30 апреля 2013 года. Самара: ПГСГА, 2013. C. $135-139$.

16. Дзамыхов А.Х. Структура и содержание методической системы совместного изучения информатики и математики в вузе // Азимут научных исследований: педагогика и психология. 2014. № 4. С. 49-53.

17. Казеев А.Е., Галкина А.В. Оценка знаний учащихся по абстрактной и компьютерной алгебре с использованием системы дистанционного обучения // Информационные технологии в социальной сфере: Материалы международной заочной научно-практической конференции. 29-30 апреля 2013 года. Самаpa: ПГСГА, 2013. С. 139-144.

18. Кондаурова И.К., Гусева М.А. Формирование у будущих педагогов-математиков умений и навыков педагога-исследователя в контексте развития профессиональной биографии // Азимут научных исследований: педагогика и психология. 2014. № 4. C. 69-72.

19. Горбатов С.В. Организация самостоятельной работы студентов на базе LMS Moodle // Информационные технологии в социальной сфере: Материалы международной заочной научно-практической конференции. 29-30 апреля 2013 года. Самара: ПГСГА, 2013. C. 116-123.

20. Кондаурова И.К. Математическая подготовка студентов в вузе в контексте будущей профессиональной деятельности // Балтийский гуманитарный журнал. 2015. № 3(12). С. 50-53.

21. Горбатов С.В., Добудько Т.В. Платформа электронного обучения Moodle как средство организации оценивания профессиональной компетенции будущего специалиста // Информационные технологии в социальной сфере: Материалы международной заочной научно-практической конференции. 29 апреля 2015 года. Самара: ПГСГА, 2015. С. 76-85. 


\title{
FEATURES OF DEVELOPMENT AND IMPLEMENTATION OF COURSES OF THE EDUCATIONAL FIELD «MATHEMATICS» IN DISTANCE EDUCATION SYSTEM
}

(C) 2016

\author{
E.L. Makarova, candidate of pedagogical sciences, \\ associate professor of the Chair of Computer Science, Applied Mathematics and Teaching Methods \\ O.I. Pugach, candidate of pedagogical sciences, \\ associate professor of the Chair of Computer Science, Applied Mathematics and Teaching Methods \\ Samara State University of Social Sciences and Education, Samara (Russia)
}

\begin{abstract}
Effective application of distance technologies, even at the level of individual courses in most universities is faced with a number of organizational, methodological problems. The final design of the regulatory framework the problem of implementation of these technologies in the field of theoretical research and experimental work in the practical implementation of the plane. The authors consider a wide range of problems arising from the mass introduction of e-learning in educational practice, their classification on various grounds. When the authors of the work are based on practical experience in the development of the course «Mathematical Foundations of Computer Science» for students training areas «Teacher Education» profiles «Informatics» and «Computer Science and Foreign Language» on the basis of a learning management system Moodle. Also studied a number of aspects related to the characteristics of the studied subject area (in «Mathematics» example of educational area). We formulate the necessary conditions for effective use of e-learning technologies. These conditions, from the point of view of the authors, speakers, among others participated in the implementation of the university administration, the formation of a uniform by the level of the basic mathematical training a group of students, the formation of a thesaurus (semantic web) course in the classroom working with students, as well as a phased approach to solving complex text assignments, requiring the construction of a formal mathematical model in the subject area. We offer some simple criteria for evaluating the effectiveness of (increased performance and students' motivation, optimization of time working teachers, reducing the number of chronic debtors in the discipline).

Keywords: distance learning; courses; introduction; educational area «Mathematics»; cost effectiveness; curriculum; work program; organization of independent work of students; examination of teaching materials; innovation; introduction of distance learning technologies; electronic educational resources.
\end{abstract}

\section{УДК 347.779}

\section{КОМПЛЕКСНАЯ ОЦЕНКА ГОТОВНОСТИ ВЫПУСКНИКОВ МАГИСТРАТУРЫ К ПРОФЕССИОНАЛЬНОЙ ДЕЯТЕЛЬНОСТИ}

(C) 2016

В.Н. Михелькевич, доктор технических наук, профессор кафедры психологии и педагогики, профессор кафедры электропривода и промышленной автоматики

П.Г. Кравцов, кандидат технических наук, доцент кафедры электропривода и промышленной автоматики Самарский государственный технический университет, Самара (Россия)

Аннотация. В соответствии с требованиями Федеральных государственных образовательных стандартов высшего образования в результате освоения программы магистратуры у выпускника должны быть сформированы общекультурные, общепрофессиональные и профессиональные компетенции по направлению подготовки, а образовательная организация обязана обеспечивать гарантию качества подготовки выпускников. Однако образовательные стандарты не регламентируют процедуру оценивания качества освоения образовательных программ, а лишь устанавливают общие требования к ней. Поэтому для аттестации обучающихся на соответствие их персональных достижений требованиям основной образовательной программы магистратуры многие вузы самостоятельно создают фонды оценочных средств, позволяющие оценить знания, умения и уровень приобретенных компетенций. В статье анализируются сложившиеся в педагогической практике системы оценивания, основанные на определении уровней освоения отдельных компонент профессиональных компетенций. Отмечается, что таким системам нередко присуща высокая трудоемкость и недостаточная комплексность при решении задачи оценивания готовности выпускников магистратуры к профессиональной деятельности. Предложено альтернативное инновационное решение этой задачи за счет использования фонда комплексных контрольных заданий в качестве диагностического инструментария при итоговой аттестации магистрантов. Это соответствует содержащимся в образовательных стандартах указаниям на то, что разрабатываемые оценочные средства должны позволять установить не только качество сформированных у обучающихся компетенций, но и степень общей готовности выпускников к профессиональной деятельности. Представлен опыт проектирования и использования в учебном процессе фонда комплексных контрольных заданий на кафедре электропривода и промышленной автоматики Самарского государственного технического университета.

Ключевые слова: выпускники магистратуры; профессиональные компетенции; комплексные контрольные задания; готовность к профессиональной деятельности; комплексная оценка готовности. 